Revista Temas Socio Jurídicos

Volumen $34 \mathrm{~N}^{\circ} 68$ Enero - Junio de 2015

pp. $107-125$

ISSN 0120-8578

\title{
IMPLICAÇÕES CONSTITUCIONAIS DO ESTADO DEMOCRÁTICO DE DIREITO AMBIENTAL
}

\author{
Cleiton Lixieski Sell \\ Fátima Fagundes Barasuol Hammarströn** \\ Recibido: Febrero 8 de 2015 \\ Aprobado: Mayo 10 de 2015
}

\section{RESUMO}

Este estudio tiene como objetivo identificar los principios que establecen Constitucional de un Estado democrático de Derecho Ambiental. En este campo del derecho ambiental, la sostenibilidad del medio ambiente viene asunción como insertado por la Constitución de 1988, contemplando un capítulo único en materia de medio ambiente que a su vez se encuentra en un contexto histórico de infringências ambientales graves causados largo de la historia. Con este fin, la investigación busca contrarrestar la importancia de un estado democrático de derecho ambiental en el contexto que azota manera conpulsiva sociedad socioeconómico, lo que lleva al caos medioambiental que una hora se ha instalado y está constantemente ampliando. Dentro de esta expectativa de un Estado democrático de ambiente equilibrado de protección, crece en importancia revisitemos conceptos como el medio ambiente, la educación ambiental, la sostenibilidad, la biodiversidad y otros, para que podamos hacer frente a los problemas ambientales actuales. Sin embarga, debe tenerse en cuenta que Brasil es un país donde prevalece la democracia, convirtiéndose en un eslabón clave entre la empresa y el deber de proteger el medio ambiente.

\footnotetext{
* Acadêmico do curso de Direito da Universidade de Cruz Alta UNICRUZ. Integrante dos Grupos de Pesquisa em Direito da Sociobiodiversidade (GPDS) e do Grupo de Pesquisas do Trabalho (GPT) da Universidade Federal de Santa Maria - UFSM. Também atua no Grupo de Pesquisa Jurídica em Cidadania, Democracia e Direitos Humanos - (GPJUR) da UNICRUZ, ambos registrados no Diretório de Grupos do CNPq. Bolsista do Programa Institucional de Bolsas de Iniciação Científica - PIBIC. cleitonls.direito@gmail.com

** Mestre em Desenvolvimento pela Universidade Regional do Noroeste do Rio Grande do Sul - UNIJUÍ ; Pesquisadora do Grupo de Pesquisa Jurídica em Cidadania, Democracia e Direitos Humanos - GPJUR; Docente da Graduação e Pós Graduação da Universidade de Cruz Alta - UNICRUZ. fatima.advocacia@hotmail.com
} 
Palabras clave: Estado Democrático. El derecho ambiental. Sostenibilidad

\title{
CONSTITUTIONAL IMPLICATIONS OF THE DEMOCRATIC STATE OF ENVIRONMENTAL LAW
}

\begin{abstract}
This study aims to identify the principles established by the Constitutional Law of a democratic State of Environmental Law. In this field of environmental law, environmental sustainability is incorporated into the 1988 Brazil Constitution, contemplating a unique chapter on the environment within a historical context of serious environmental violations caused along history. For this purpose, the research seeks to counteract the importance of a democratic state of environmental law in the context of a socioeconomic model that leads permanently to environmental chaos. The expectation of a democratic state of balanced environmental protection grows in importance. This text refers to concepts such as environment, environmental education, sustainability, biodiversity and others, in order to face current environmental problems. However, it should be noted that Brazil is a country where democracy prevails, becoming a key link between the company and the duty to protect the environment.
\end{abstract}

Key words: Democratic State. Environmental Law. Sustainability.

\section{INTRODUÇÃO HISTÓRICA SOBRE OS PRINCIPAIS DESATRES AMBIENTAIS}

O tema deste trabalho começou a partir da observação de que os recursos naturais que até o século passado parecia inesgotável, estão chegando a um limite crítico, ou seja, a uma verdadeira crise social e ambiental pela sociedade moderna regida por uma racionalidade puramente económica que buscar a satisfação das necessidades dos consumidores insaciáveis, é a natureza degradante, sem qualquer preocupação com as consequências, pois se antes parecia distante, agora está muito mais perto.

Isto levou ao Direito Ambiental do Estado Democrático passando por uma reestruturação de seu papel na sociedade sobre as questões relacionadas ao meio ambiente, uma vez que, em conjunto com todas as 
partes interessadas nas questões de proteção ambiental, o Estado é responsável constitucionalmente garantir meio ambiente ecologicamente equilibrado, o que pode garantir uma boa qualidade de vida, não só para os seres existentes hoje, mas também aqueles que lhes sucedem no futuro próximo ou longo. Para tornar isso possível, a participação da sociedade como sujeitos ativos desta transformação é essencial, juntamente com a criação de um novo paradigma de desenvolvimento sustentável.

Segundo Sirvinskas (2007), ao longo do tempo, com o advento e a evolução dos meios de comunicação, o meio ambiente passou a ser contaminado através das mais diversas maneiras, como por elementos nucleares, químicos, domésticos, industriais, hospitalares entre outros.

Em relação as políticas de proteção do meio ambiente, o primeiro grande passo dado no tocante a Educação ambiental foi a Lei da Política da Educação ambiental ${ }^{1}$, no qual faz saber que incumbe ao Poder Público estimular a educaçãoambiental em todos níveis possíveis de ensino, inclusive em outras linguas.

Ainda está registrado na Constituição Federal de 1988 o direito de todos com a proteção do meio ambiente. Para fins de estudo, conservar tem o significado de explorar os recursos naturais de forma racional sem causar impactos profundos. No tocante aos desastres que marcaram a história, dentre os piores desastres, está o acontecimento em dezembro de 1984, qual seja o vazamento de gases letais da fábrica Union Carbide Corporation, onde estima-se que após o acontecimento cerca de 8000 pessoas vieram a morrer devido ao lançamento de gazes tóxicos na atmosfera. Segundo informações que foram obtidas após análises feitas para apurar a responsabilidade, ficou evidenciado que os sistemas de segurança, criados para possíveis acidentes que poderiam ocorrer, encontravam-se desligados. Os efeitos dessa catástrofe permeiam até os dias atuais, pois aproximadamente 150 mil sobreviventes do desastre convivem hoje com doenças crônicas, necessitando ainda de cuidados médicos, bem como, os efeitos estende-se a segunda geração de crianças que tiverem seus pais envolvidos no mais desumano desastre que ocorreu na Índia. (Greenpeace. S.f)

Em 1986, na usina nuclear de Chernobyl (Sousa, s.f.), situada na Ucrânia, onde os operadores realizaram um experimento com um reator.

1 BRASIL. Lei $\mathbf{n}^{0}$ 9.795, de 27 de abril de 1999. Dispõe sobre a Educação Ambiental. Disponível em: $<$ http://www.planalto.gov.br/ccivil_03/leis/19795.htm>.Acesso em: 8 fev. 2015. 
No entanto, para que o teste posse possível seria necessário quebrar normas de segurança da usina, interrompendo a circulação do sistema hidráulico que era responsável pela temperatura do reator. Devido a tal interrupção fez com que fosse ocasionado um superaquecimento incapaz de ser revertido levando ao surgimento de uma imensa bola de fogo que veio a explodir liberando de seu interior Césio-137, um elemento químico altamente radioativo. A liberação de grande quantidade de letal material radioativo na atmosfera contaminou uma extensão quilométrica, sendo comparado a 400 vezes maior do que os efeitos das Bombas de Hiroshima e Nagasaki no Japão, ao final da segunda GrandeGuerra.

Após diversos estudos realizados por especialistas, os efeitos atingiram os descendentes das pessoas que foram afetadas, gerando problemas congênitos e anomalias genéticas ocasionandas por esse e outros fatores como o surgimento dos conflitos dos ambientalistas para a construção de novas usinas nucleares em diversas partes do mundo.

Em novembro de 1986, um incêndio a fábrica Sandoz de pesticidas provocou um derramamento de 30 toneladas de pesticidas no Rio reno, causando mortandade de peixes ao longo de $193 \mathrm{Km}$. O cenário era assustador, pois a água do rio era coberta por uma mancha escura sem qualquer visibilidade, vindo a mover a população local e causar um impacto ambiental incalculável. (Gerstenberg, 1986)

Ainda outro fato gerador de grande discussão é referente ao navio Exxon Valdez (Greenpeace, sf.), pois transportava petróleo do mundo, vindo a derramar em pleno Alaska (EUA), aproximadamente 41 milhões de litros de petróleo, afetando a vida selvagem lá existente. Esse navio petroleiro, era o maior companhia petrolífera do mundo, empresa essa que hoje comercializa os produtos derivados do petróleo sob a marca ESSO.

No ano de 1991, a ExxoMobil foi considerada culpada pela derramamento do navio petroleiro, infringindo inúmeras leis ambientais, sendo imputado um valor de 1 bilhão de dólares de multa. Essa punição registra a maior punição que uma empresa já sofreu, pois, além do valor da indenização, a área ficou por algum tempo sem vida animal, e ainda continua em fase de recuperação.

A respeito dos movimentos de discussão dos problemas ambientais, podem ser citados a Conferência das Nações Unidas sobre Meio 
Ambiente e Desenvolvimento no ano de 1992 - ECO-92, onde novamente foi mencionado a situação da proteção por parte dos países para com o mundo, tendo sido estipulados oficialmente orientações e responsabilidades que devem ser executadas por todos os participantes do evento. Logo em seguida vem a chamada "Agenda 21", que nada mais é do que a minuciosa diretriz que foi determinada como prioridade para realizar cada um dos vetores que foram levantados na Conferência das Nações Unidas.

A pesquisa foi realizada através da revisão bibliográfica de autores renomados que discutem o tema em questão, tendo como indicativo o método dedutivo, também conhecido por alguns autores como hipotético. Com a fundamentação nesse método, fundamentou-se a partir de leituras e fichamentos de autores que abordam o tema em questão, construindo-se hipóteses que foram confrontadas com as informações obtidas pelas leituras realizadas.

\section{A SUSTENTABILIDADE AMBIENTAL E OS SABERES DO ESTADO DEMOCRÁTICO DE DIREITOAMBIENTAL}

A possibilidade de um desenvolvimento social em todos os seus aspectos, inclusive econômico, que aconteça de uma forma onde os recursos ambientais sejam utilizados com racionalidade e inteligência, onde a satisfação das necessidades das gerações atuais não comprometa o futuro das próximas gerações é que denomina-se de sustentabilidade ambiental.

A principal finalidade da sustentabilidade é garantir um planeta futuro com condições adequadas para a existência das mais diversas formas de vida mediante a garantia de recursos naturais essenciais para uma qualidade de vida adequada. Dentro dessa espectativa, a busca por um desenvolvimento sustentável segundo Leff (2009 b), traz a concepção de um saber ambiental, onde as ações do mundo atual perpassem por reflexões sobre a evolução social e econômica da situação em que se encontra o meio ambiente, especialmente com um olhar voltado para os principais elementos que constituem a atual crise ambiental, como a degradação ambiental, o risco de um colapso ecológico e o avanço da desigualdade e da pobreza.

Nestes tempos está se forjando o saber ambiental, [...], saber sobre um ambiente que não é a realidade visível da poluição, 
mas o conceito da complexidade emergente onde se reencontram o pensamento e o mundo, a sociedade e a natureza, a iologia e a tecnologia, a vida e a linguagem. [...]. De um saber atravessado por estratégias de poder em torno da reapropriação (filosófica, epistemológica, econômica, tecnológica e cultural) da natureza (Leff, 2009 b, p. 10).

Contudo para que se possa falar em um saber ambiental é imprescindível que se analise o mercado globalizado, do atual conhecimento científico e da racionalidade instrumental e econômica, uma vez que somente com o entendimento da complexidade destes é que se é possível atingir uma racionalidade ambiental que tem como essência um desenvolvimento sustentável.

Neste contexto, o papel do Estado Democrático de Direito Ambiental é de fundamental importância, tanto a Carta Magna Brasileira estabelece de forma clara e taxativa o dever do Estado e da coletividade de garantir uma qualidade de vida ecologicamente equilibrada.

\section{A GLOBALIZAÇÃO E O CONSUMO SUSTENTÁVEL}

A globalização vem tomando espaço a partir da segunda metade do século XX, trazendo como principais características a instantaneidade nas relações, de forma especial no campo das relações econômicas de diferentes países. A rapidez e o acesso facilitado da informação possibilitam que os mais diversos fatos aconteçam simultaneamente em diversos países e de forma interligada, tendo como consequência direta o comprometimento dos recursos naturais.

O desenvolvimento econômico globalizado é o principal propulsor das desigualdades sociais, que é uma das principais causas da crise ambiental, uma vez que leva a crise da civilização; assim a "[...] a degradação ambiental se manifesta como sintoma de uma crise de civilização, marcada pelo modelo de modernidade regido prelo predomínio do desenvolvimento da razão tecnológica sobre a organização da natureza" (Leff, 2009 b, p. 17).

Essa forma de desenvolvimento econômico apresentada pela globalização leva a um grave paradoxo, de um lado tem uma sociedade que busca um consumo insaciável, onde os desejos consumeiristas ultrapassam as reais necessidades; e de outro temos recursos naturais limitados e finitos; e, tudo isso leva a tão discutível crise da civilização e 
consequentemente a crise ambiental. Milaré (2005) enfatiza que a sociedade atual passa por um momento em que há um culto ao consumismo associado a criação de necessidades desnecessárias.

[...] fizemo-nos reféns de um modelo civilizatório depredador e consumista que, se universalizado, demandaria três planetas semelhantes ao nosso. [...] Evidentemente isso é impossível, o que comprova a falta completa de sustentabilidade de nosso modo de produção, distribuição e consumo de bens e serviços. Não são poucos os analistas do estado da Terra que advertem: ou mudamos de padrão de relacionamento com a Terra ou vamos ao encontro do pior (Boff, 2003, p. 36).

O estilo de vida consumista que caracteriza a sociedade atual traz, conforme Trigueiro (2012), três armadilhas, quais sejam, a primeira éticomoral, onde se tem a necessidade de ostentar abundância onde há escassez, a segunda ecológica, onde o consumo desenfreado leva a devastação e destruição de recursos naturais finitos; e a terceira de ilusão, uma vez que a felicidade e a paz estão associadas à aquisição de bens materiais.

Contudo, mesmo diante da constatação das consequências nefastas que a globalização, especialmente com seu modelo econômico consumista trouxe, é plenamente possível associar esse desenvolvimento com um consumo sustentável, mediante uma economia e um uso racional de energia e matéria-prima e a conservação dos recursos naturais de forma a respeitar os ecossistemas (Milaré, 2005).

Essa concepção de um desenvolvimento sustentável racional vem ao encontro da concepção de saber ambiental, onde segundo Leff (2006, p. 13), "[...] trata-se da reapropriação da natureza e da reinvenção do mundo; não só de 'um mundo no qual caibam muitos mundos', mas de um mundo conformado por uma diversidade de mundos, abrindo o cerco da ordem econômica-ecológica globalizada".

No Brasil foi criada em 2001 uma organização não-governamental e sem fins lucrativos denominada de Instituto Akatu, o qual tem por finalidade desenvolver um consumo consciente. De acordo com dados apresentados por tal instituto em parceria com o Relatório Estado do Mundo 2010, publicado pelo Worldwatch Institute, a humanidade está consumindo $50 \%$ a mais do que a natureza consegue renovar, sendo que $16 \%$ da população mundial é responsável por $78 \%$ do consumo total da humanidade. 
Em contrapartida, a mesma pesquisa constatou que no Brasil, $28 \%$ dos consumidores estão praticando um consumo consciente, o que demonstra que, mesmo de forma ainda bastante reduzida, a sociedade já começou a perceber os danos que um consumo desenfreado pode causar ao meio ambiente.

O Instituto Akatu acrescenta à política dos já conhecidos e difundidos $3 R^{\prime} s$ - reduzir, reutilizar e reciclar - um $4^{\circ} \mathrm{R}$, qual seja, repensar; o que certamente é o ponto de partida para o consumo consciente, uma vez que com a reflexão no ato do consumo é o primeiro passo para a adoção de uma postura equilibrada frente as reais necessidades e a disponibilidade dos recursos naturais (Trigueiro, 2012).

Desta forma, para Leff (2009 b) é possível uma sustentabilidade ecológica no contexto da globalização como forma de sobrevivência da humanidade o que deve decorrer de um esforço conjunto entre as nações, na busca de um crescimento econômico sustentado. Esta sustentabilidade

[...] busca conciliar os contrários do desenvolvimento: o meio ambiente e o crescimento econômico [...]; seu intuito não é internalizar [...] mas proclamar o crescimento econômico como um processo sustentável, firmados nos mecanismos do livre mercado como eficaz de assegurar um equilíbrio ecológico e a igualdade social (Leff, 2009 b, p. 26/27).

O desenvolvimento sustentável na era da globalização precisa atingir a economia global, também denominada de economia verde, a qual deve ter por finalidade propor que, além das tecnologias produtivas e sociais, sejam criados meios pelos quais fatores essenciais ligados à sustentabilidade socioambiental, hoje ignorada nas decisões econômicas passem a ser considerados.

\section{A CRISE SOCIAL E A FUNÇÃO DO ESTADO DEMOCRÁTICO DE DIREITO AMBIENTAL E DA C OL E T IVID A D E NA IM PLEMENTAÇÃ O D O DESENVOLVIMENTOSUSTENTÁVEL}

Os números dessa crise social são aterrorizantes, uma vez que de acordo com as estimativas da Organização Internacional do Trabalho(OIT), são 200 milhões de desempregados e ao mesmo tempo, o Relatório das 
Nações Unidas estima 2 bilhões de pessoas está vivendo estão vivendo abaixo da linha da pobreza.

Essa grande massa da sociedade que são os atores da crise social, vivem em condições completamente desfavoráveis, e são essas condições que acabam por gerar danos ambientais, como a questão da ausência de saneamento básico que leva não só ao surgimento de doenças e morte dessas pessoas, como também é fator de poluição do ar.

De acordo com Veiga (2005) são necessárias transições interligadas que podem ensejar um desenvolvimento sustentável, dentre elas uma sustentabilidade maior decorrente de uma estabilização populacional e a distribuição equitativa das riquezas com uma visão especial para a população que vive na margem da pobreza.

A menos que as pessoas pobres e marginalizadas possam influenciar ações políticas de âmbito local e nacional, não é provável que obtenham acesso equitativo ao emprego, escolas, hospitais, justiça, segurança e outros serviços básicos (Veiga, 2005, p. 81).

Frente a tais cenários, a problemática da sustentabilidade passou a ser um foco de reflexão crítica em torno das dimensões do desenvolvimento e atuação das políticas públicas e da sociedade, especialmente face a todas as garantias normativas de proteção ao ambiente, seja ele natural ou artificial, que se pressupõem como um dos elementos constitutivos do Estado Democrático Direito Ambiental.

A discussão sobre políticas públicas ambientais somente passou a figurar no cenário internacional depois de vinte anos passados do Relatório de Brundtland de 1997 e em virtude de muita discussão e esforço por parte da Comissão Mundial de Meio Ambiente das Nações Unidas. A partir daí, então, começaram a ser discutidas políticas alternativas que buscassem uma mudança significativa no estilo de desenvolvimento (Ferreira, 2003).

Já no âmbito brasileiro, a Constituição Federal de 1988 em seu artigo 225, impõe ao Poder Público, juntamente com a coletividade, o dever de adotar medidas que assegurem um meio ambiente ecologicamente equilibrado buscando assim um efetivo Estado Ambiental de Direito, o qual “[...] só pode existir dentro de uma ótica democrática, garantindo-se o direito de participação popular" (Araújo, 2008,p. 02). 
A implementação de políticas públicas voltadas ao meio ambiente não significa um entrave para o desenvolvimento econômico, o que se busca com as mesmas é possibilitar que as futuras gerações efetivem seu direito ao meio ambiente protegido, tendo acesso a todos os recursos ambientais necessários para a manutenção da vida.

Nessa direção, torna-se necessária uma iniciativa criativa, inovadora e inclusiva que permita o engajamento de todos os atores sociais relevantes, desde governos, instituições internacionais, sociedade civil, setor empresarial, com a finalidade de enfrentar a grande demanda ética da Humanidade: conferir a cada indivíduo desse planeta um sentido existencial que lhe permita viver com dignidade (Fledmann, 2003, p. 157).

Leff (2006) apresenta com propriedade algumas formas de enfrentar os desafios da sustentabilidade, quais sejam: a economia ambiental que procura incorporar as condições ambientais da sustentabilidade, através de uma avaliação de custos e benefícios ambientais e sua tradução em valores econômicos e preços de mercado; a economia ecológica que estabelece o limite entrópico do processo econômico e a incomensurabilidade entre os processos ecológicos e os mecanismos do mercado, procurando desenvolver um novo paradigma que integre processos econômicos, ecológicos, energéticos e populacionais; e a possibilidade de pensar e construir uma nova racionalidade produtiva, fundada na articulação de processos ecológicos, energéticos e culturais que constituem um potencial ambiental de desenvolvimento sustentável.

Todas essas questões perpassam pela formação de um novo saber, um saber que se fundamente em um referencial empírico que é a realidade social, a qual é construída com base em juízos de valores e na interdisciplinaridade do conhecimento; um saber que problematize o conhecimento fragmentado e busque a construção de um novo conhecimento teórico e prático que rearticule as relações do homem com a natureza; saber este denominado por Enrique Leff de SABER AMBIENTAL.

\section{DEMOCRACIA AMBIENTAL, RACIONALIDADE AMBIENTAL, CONSCIÊNCIA AMBIENTAL E SUA CONTRIBUIÇÃO NA QUALIDADE DE VIDA}

Os princípios da racionalidade econômica e instrumental formaram o alicerce da civilização moderna, fazendo com que os custos 
socioambientais derivados dessa racionalidade produtiva obrigassem à incorporação de normas ecológicas ao processo econômico, ampliando com isso o conceito de ambiente.

Desta forma, a sociedade atual tem por base pressupostos éticos baseados em uma racionalidade econômica e no direito privado, razão pela qual as condições ecológicas de sustentabilidade são ignoradas, gerando uma destruição de valores, o que somente pode ser mudado mediante uma democracia ambiental que desenvolva uma racionalidade ambiental que decorra de um desenvolvimento sustentável que propicie "[...] novos princípios aos processos de democratização da sociedade que induzem à participação direta das comunidades na apropriação e transformação de seus recursos ambientais" (LEFF, 2009, p. 60).

Esse processo de transição da racionalidade econômica ou instrumental para a racionalidade ambiental se dá mediante a construção de um saber ambiental que problematiza as questões ambientais, buscando a integração de um conhecimento complexo que transcende a realidade atual.

\section{A RACIONALIDADE AMBIENTAL COMO PRESSUPOSTO DOSABERAMBIENTAL}

[...], a racionalidade ambiental se funda numa nova ética que se manifesta em comportamentos humanos em harmonia com a natureza; em princípios de uma vida democrática e em valores culturais que dão sentido a existência humana. Esses se traduzem num conjunto de práticas sociais que transformam as estruturas do poder associadas à ordem econômica estabelecida, mobilizando um potencial ambiental para a construção de uma racionalidade social alternativa (Leff, 2009 b, p. 85).

Essa realidade é geradora de uma sociedade onde a vida humana está estritamente vinculada as satisfações dos interesses de consumo e a uma globalização econômica em que os interesses do mercado se subjuga os saberes, degrada a qualidade de vida mediante a utilização desenfreada dos recursos naturais que traz como consequência direta a pobreza, em suas mais amplas interpretações e a degradação e destruição dos ecossistemas.

A urbanização desenfreada decorrente do aglomero de produção, do consumo desregrado e o próprio progresso com a acumulação de 
irracionalidades é a principal característica da racionalidade econômica, onde a natureza é submissa a leis do mercado, colocando em risco a própria sobrevivência do planeta. Desta forma,

Se o crescimento econômico não é sustentável e se a racionalidade econômica não contém os mecanismos para uma desativação, então é necessário construir outra racionalidade produtiva que possa operar conforme os princípios da sustentabilidade. [...], é necessário formular uma nova economia que funcione sobre a base dos potenciais ecológicos do planeta, do poder do saber, da ciência e tecnologia, e das formas culturais de significação da natureza (LEFF, 2006, p. 222).

Se o crescimento econômico não é sustentável e se a racionalidade econômica não contém os mecanismos para uma desativação, então é necessário construir outra racionalidade produtiva que possa operar conforme os princípios da sustentabilidade. "[...], é necessário formular uma nova economia que funcione sobre a base dos potenciais ecológicos do planeta, do poder do saber, da ciência e tecnologia, e das formas culturais de significação da natureza"(Leff, 2006, p. 222).

Toda racionalidade social articula um sistema de teorias e conceitos, de normas jurídicas e instrumentos técnicos, de significações e valores culturais, estabelecendo critérios e assim, legitimando as ações dos agentes sociais na busca de um desenvolvimento sustentável que implique "[...] na superação da racionalidade econômica: não pela rejeição da eficiência econômica e nem pela abdicação do crescimento econômico, mas pela colocação dos mesmos a serviço de um novo projeto societário" (Leff, 2008, p. 27).

Não obstante, a transição para essa racionalidade ambiental é um dos elementos de construção de um saber ambiental que é internalizado pelos atores sociais, uma vez que

[...] a retotalização do saber proposta pela problemática ambiental é mais do que a soma e a articulação dos paradigmas científicos existentes; implica internalizar o saber ambiental emergente. A necessária inter e transdisciplinaridade do saber ambiental trasncende os alcances de um paradigma globalizante, a unificação das homologias estruturais de diferentes teorias, ou a integração 
dos saberes diversos por uma metalinguagem comum (Leff, 2009 b, p.148).

A racionalidade ambiental fundamenta-se em valores éticos e critérios que atualmente não são considerados pela racionalidade econômica, e se constrói tendo por base uma inter-relação entre a teoria e prática, mediante a presença de requisitos como a formação de uma consciência ecológica, o planejamento transetorial da administração pública, a participação da sociedade na gestão dos recursos ambientais e a reorganização interdisciplinar do saber, tanto na produção quanto na aplicação do conhecimento.

Nesse sentido, a racionalidade ambiental é articulada em quatro esferas de racionalidade: a racionalidade substantiva, a qual define os valores e objetivos que norteiam as ações sociais direcionadas à construção da racionalidade ambienta, visando a construção de "[...] uma teoria crítica da produção e do desenvolvimento sustentável” (Leff, 2009 b,p. 139).

A racionalidade teórica, que sistematiza os valores da racionalidade substantiva relacionando-os com questões culturais, políticas, econômicas, ecológicas, além de dar sustentação a construção de uma nova racionalidade social e produtiva, mediante a criação de critérios avaliativos dos projetos e formas alternativas de desenvolvimento; a racionalidade instrumental, que visa os meios técnicos, funcionais e operacionais que dão sustentação ao desenvolvimento sustentável, bem como a implementação eficaz de estratégias que mobilizem os atores sociais na promoção de políticas públicas que possibilitem a operacionalização da racionalidade ambiental; e a racionalidade cultural, a qual é um sistema de significados que traduz a identidade cultural de cada povo, possibilitando práticas sociais coerentes com os potenciais geográficos e os recursos naturais, e isso decorre de uma educação ambiental com novos objetivos interdisciplinares que questionem os paradigmas dominantes e incorpore na prática docente e nos programas curriculares o saber ambiental.

A construção da racionalidade ambiental decorre da integração de diferentes esferas da racionalidade, inclusive a esfera da racionalidade econômica, uma vez que "[...] nas práticas de apropriação e transformação da natureza se confrontam e amalgamam diferentes racionalidades: a racionalidade capitalista de usos dos recursos; a racionalidade ecológica das práticas produtivas; a racionalidade dos estilos éticos de uso da natureza" (Leff, 2009 b, p. 142). 
A passagem da racionalidade capitalista para uma racionalidade ambiental caracteriza-se por um processo de transição, onde, mesmo ambas se antagonizando em diversos aspectos, deve ser reconhecida a complementariedade entre elas.

Isso pressupõe a desconstrução da racionalidade capitalista para uma reconstrução econômica basilada na equidade e na sustentabilidade, o que é possível mediante uma gestão participativa e democrática dos recursos ambientais.

Assim, para que seja desconstruída a racionalidade capitalista é necessária a construção de uma racionalidade social onde o paradigma ambiental se sobrepõe aos efeitos da produtividade e da busca pelo lucro, qual seja a racionalidade ambiental.

\section{A RACIONALIDADE AMBIENTAL COMO FORMA DE REAPROPRIAÇÃO DO MEIOAMBIENTE}

A atual problemática ambiental trouxe consigo a necessidade de buscarem-se meios de evitar o esgotamento dos recursos naturais mediante uma utilização racional e uma produção sustentável, sem com isso desconsiderar a necessidade do desenvolvimento econômico.

O discurso dominante da sustentabilidade promove um crescimento econômico sustentável, eludindo as condições ecológicas e termodinâmicas que estabelecem limites e condições à apropriação e transformação capitalista da natureza. [...]. O discurso da sustentabilidade busca conciliar os contrários do desenvolvimento: o meio ambiente e o crescimento econômico. [...]; seu intuito não é internalizar [...] mas proclamar o crescimento econômico como um processo sustentável, firmados nos mecanismos do livre mercado como eficaz de assegurar um equilíbrio ecológico e a igualdade social (Leff, 2009 b, p. 23/26-27).

Na busca de uma solução palpável para a integração entre um desenvolvimento sustentável e um desenvolvimento econômico, surgiu a figura do ecodesenvolvimento, termo proposto por Maurice Strong, difundido por Ignacy Sanches e acolhido por Leff, o qual, além da preocupação com o meio ambiente, incorporou as devidas atenções às questões sociais, econômicas, culturais, de gestão participativa e ética como uma forma de reapropriação da natureza. 
A teoria do ecodesenvolvimento traz uma nova concepção ética para natureza, a qual se baseia na conservação dos recursos renováveis e no não desperdício dos recursos não renováveis.

Desta forma, ao propor uma nova racionalidade produtiva, o ecodesenvolvimento é um dos elementos que compõe o saber ambiental, uma vez que visa internalizar o meio ambiente no processo econômico, com fundamentos e instrumentos teóricos e práticos, sem desconsiderar as questões epistemológicas, institucionais e políticas.

Aliado do desenvolvimento sustentável, o ecodesenvolvimento pressupõe transformações institucionais, jurídicas e políticas, visando uma apropriação da natureza. Novos comportamentos dos atores sociais que visem o enfrentamento da racionalidade econômica, voltada exclusivamente para o consumo e o lucro, são objetivos do ecodesenvolvimento visando mudanças no campo das lutas sociais que possibilitem aos indivíduos a apropriação de seu patrimônio de recursos naturais e culturais.

Boff questiona o atual modelo de desenvolvimento sustentável, no qual a relação atual do homem com a natureza continua ocorrendo de forma exclusivamente utilitarista; sendo assim, o desenvolvimento de uma sustentabilidade que garanta o equilíbrio entre as necessidades humanas e os recursos naturais, é uma questão de vida ou morte. "Esquecemos que nós somos parte da natureza e que ela não é composta apenas pelos seres humanos. Todos os seres são interdependentes e formam a comunidade de vida. A rede, que desta conectividade se deriva, é responsável pelo equilíbrio da vida e do planeta" (2012, p. 38)

A democracia ambiental onde ocorre a participação direta da sociedade na gestão e manejo dos recursos naturais, mediante uma desconcentração de poder e uma descentralização da economia, são pressupostos para uma reapropriação não só da própria natureza como também da capacidade de intervenção na vida política e na elaboração dos processos produtivos. Esse processo se dá por meio da racionalidade ambiental.

A racionalidade ambiental que daí emerge se distância de uma concepção conservadora e produtivista da natureza para converter-se em uma estratégia para a reapropriação social da natureza, baseada na valoração cultural, econômica e tecnológica dos bens e serviços ambientais da natureza. A 
racionalidade ambiental desemboca em uma política do ser, da diversidade e da diferença que reformula o valor da natureza e o sentido da produção (Leff, 2006, p. 69).

Leff (2006, p. 208) ainda reitera que "[...] a construção da sustentabilidade estará guiada por uma ressignificação e revalorização social da natureza que haverá de conduzir até a apropriação cultural dos processos ecológicos".

Dessa forma os valores ecológicos e os direitos culturais trazidos pela nova concepção de racionalidade, qual seja, a racionalidade ambiental, muitas vezes confrontam-se com valores culturais tradicionais que defendem acirradamente a racionalidade econômica na forma vigente nos dias atuais.

Somente desta maneira é possível se chegar a uma qualidade de vida que ultrapasse as diferenças e possibilite a reapropriação da natureza.

\section{CONCLUSÃO}

A devida proteção do meio ambiente é dever fundamental de todos, pois afeta o desenvolvimento econômico do mundo inteiro; desta forma o homem, através de constantes avaliações das mudanças que ocorreram, descobrem ou inventam novos métodos mais eficientes e eficazes para chegar a uma uma conscientização da necessidade de conservação ambiental. No entanto, para se chegar a uma expectativa de melhorar este cenário catastrófico, é preciso que se aceite a responsabilidade por parte da espécie humana em todos os níveis e classes sociais.

Diante dos aspectos mencionados, uma das formas que se tem de fazer com que as desigualdades sociais possam ser enfrentadas, ou pelo menos amenizadas, e, consequentemente, se atinja um desenvolvimento sustentável, é através de políticas públicas integradoras e participativas, onde os principais atores - a sociedade em geral - tenha influente papel no processo decisório.

Contudo torna-se imprescindível o registro de que muitas foram as indagações as quais nos propusemos a responder ao longo do mesmo, das quais muitas continuaram em aberto. Isso decorre do fato de que as questões que envolvem o meio ambiente, a sustentabilidade e a possibilidade de um desenvolvimento sustentável, com a intervenção direta de todos os atores envolvidos, especialmente o Estado 
Democrático de Direito Ambiental desenvolvendo seu papel, ainda estão em fases muito latentes.

Assim, além de não terem sido respondidas todas as questões iniciais, muitas outras ainda surgiram no decorrer das leituras e elaboração do texto; contudo, isso não tem um aspecto negativo, pelo contrário, pois tais constatações serviram para comprovar a teoria de Morin, defendida por Leff, de que o saber ambiental, como forma de um novo atuar social junto ao meio ambiente, precisa passar pela desconstrução de conceitos predefinidos, para somente assim, serem construídos novos paradigmas ambientais, onde a racionalidade econômica passe a estar associada a racionalidade ambiental, uma vez que um desenvolvimento amparado na inter-relação de ambas é que poderá ser chamado de um desenvolvimento sustentável.

As questões ambientais não podem ser analisadas de por regionalizada ou territorializada, pois elas ultrapassam fronteiras, o que forçou os países ao reconhecimento de que não é possível fragmentar e individualizar os problemas ambientais tendo por parâmetro a individualidade de cada Estado-Nação. O meio ambiente é um bem coletivo que não se encontra delimitado por demarcações fronteiriças e que a sua conservação perpassa o âmbito internacional, gerando impacto político, social e econômico a todos os Estados.

No entanto, somente mediante uma visão local, articulada com as dimensões globais das questões ambientais é que será possível resguardálo para as futuras gerações, garantido assim o Estado aquilo que lhe é exigido pela Constituição Federal Brasileira, qual seja, o dever de propiciar a todo o cidadão, das gerações presentes e futuras, um meio ambiente sadio e equilibrado que lhes possibilite uma qualidade de vida digna.

Catástrofes como o acidente ocorrido na usina nuclear de Chernobyl, que liberou material radioativo, o incêndio a fábrica Sandoz de pesticidas, vindo a atingir as aguas causando a mortandade de toneladas de peixes, ou o derramamento de petróleo navio Exxon Valdez, no Alaska, vindo a derramar mais de 40 milhões de litros de petróleo, em fim, são exemplos reais do poder do homem sobre a natureza.

\section{REFERÊNCIAS BIBLIOGRÁFICAS}

BRASIL. (1988)Constituição Federal. Brasília: Senado Federal, 1988. Disponível em: <http://www.planalto.gov.br/ccivil_03/constituicao/ constituicao.htm $>$ 
. (1999), Lei $n^{\circ}$ 9.795, de 27 de abril de 1999. Dispõe sobre a Educação Ambiental. Disponível em: <http://www.planalto.gov.br/ ccivil_03/leis/19795.htm>

ARAÚJO, T. C. d'Á. (2008), Tridimensionalidade Principiológica da Democracia Ambiental. Revista Fórum de Direito Urbano e Ambiental. Belo Horizonte: Fórum. v 37. jan./fev.

BOFF, L. B. (2013). Ecologia e Espiritualidade. In: TRIGUEIRO. André. (Org.). Meio Ambiente do Século 21. Rio de Janeiro: Sextante.

GERSTENBERG, F. 1986: Catástrofe ecológica no Reno. Disponível em: <http://www.dw.de/1986-cat\%C3\%A1 strofe-ecol\%C3\%B3gicano-reno/a-666757-1?maca=bra-uol-all-1387-xml-uol>. Acesso em: 8 fev. 2015.

GREENPEACE. Bhopal, Índia, O pior desastre químico da história 1984 - 2002. Disponível em: <http://www. greenpeace.org.br/bhopal/ docs/Bhopal_desastre_continua.pdf $>$.Acesso em: 8 fev. 2015 .

GREENPEACE. Desastre do Exxon Valdez: uma contínua história de mentiras. Disponível em: <http://www.greenpeace.org.org/brasil/pt/ Noticias/desastre-do-exxon-valdez-uma/>. Acesso em: 8 fev. 2015.

LEFF, H. (2006). Racionalidade Ambiental: a Reapropriação Social da Natureza. (2006). São Paulo: Civilização Brasileira.

. Ecologia, Capital e Cultura: a territorialização da racionalidade ambiental.(2009 a). Petrópolis: Vozes.

- Saber Ambiental: Sustentabilidade, Racionalidade, Complexidade, Poder.(2009 b). Petrópolis: Vozes.

FERREIRA, L. da C. (2003). A questão Ambiental: Sustentabilidade e políticas públicas no Brasil. São Paulo: Boitempo.

FLEDMANN, F. (2003). Consumismo. In: TRIGUEIRO. André. (Org.). Meio Ambiente do Século 21. Rio de Janeiro: Sextante.

MILARÉ, E. (2005). Direito do Ambiente: Doutrina, prática e jurisprudência. $4^{\mathrm{a}}$. ed. rev. atual. e ampl. São Paulo: Revista dos Tribunais, 2005. 
SIRVINSKAS, L. P. (2007). Manual de Direito Ambiental. $5^{\text {a }}$. ed. rev. e atual. São Paulo: Saraiva.

SOUSA, R. Acidente de Chernobyl. Disponível em: $<$ http://www.brasil escola.com/historia/chernobyl-acidente-nuclear.htm $>$. Acesso em: 8 fev. 2015.

TRIGUEIRO, A. (2012) Mundo Sustentável 2: novos rumos para um planeta em crise. São Paulo: Globo.

VEIGA, J. E. da. (2005). Desenvolvimento Sustentável: o desfio do século XXI. Rio de Janeiro: Garamond. 